\title{
Valor e comunicação no capitalismo globalizado ${ }^{1}$
}

\author{
José Luiz Aidar Prado² \\ PUC-SP \\ zupra@terra.com.br \\ Edílson Cazeloto 3 \\ PUC-SP \\ edcazeloto@yahoo.com.br
}

\begin{abstract}
Resumo: Esse texto busca situar a comunicação como campo de construção do valor na lógica do capitalismo globalizado. $O$ papel da comunicação no mundo atual exige, para a compreensão do processo de valorização da mercadoria, uma teoria que não seja estritamente economicista, assumindo a necessidade de nutrir-se de um conjunto de teorias vindas de campos como a filosofia e a sociologia, entre outros, incluindo as novas sociabilidades da multidão. Para efetivar tal análise, partiremos da teoria marxista do valor, examinaremos as críticas de André Gorz, Paolo Virno, Wolfgang Haug e outros, ao tematizarem as mudanças nos processos de constituição do valor no capitalismo contemporâneo pós-moderno, centralizado em processos de comunicação e semiotização da mercadoria, assim como de mercantilização da cultura. Para entender a nova sociabilidade contemporânea, examinaremos as relações entre mundo da vida e sistema, bem como a nova constituição do "intelecto geral" de Virno.
\end{abstract}

Palavras-Chave: Globalização.Valor. Sociedade da comunicação.

Abstract: Value and communication in globalized capitalism - This text attempts to regard communication as a field for the construction of value, within the logic of current globalized capitalism. The role of communication in the world today demands, in order to understand the process of merchandise valuation, a theory which should not be strictly economicist, but should take recourse to a set of theories from fields such as philosophy and sociology, among others, including the new sociabilities of the crowd. In order to carry out such analysis, we will depart from the Marxian theory of value, we will examine the critiques put forward by André Gorz, Paolo Virno,

\footnotetext{
${ }^{1}$ Trabalho apresentado ao Grupo de Trabalho "Comunicação e sociabilidade", do XV Encontro da Compós, na Unesp, Bauru, SP, em junho de 2006.

${ }^{2}$ José Luiz Aidar Prado é professor doutor do programa de Pós-graduação em Comunicação e Semiótica da PUC-SP, autor de Brecha da comunicação, co-autor de Zizek crítico, Lugar global lugar nenhum, entre outros, e coordenador do Grupo de Estudos em Mídia Impressa (que realiza a pesquisa A invenção do Outro e do Mesmo na mídia semanal, projeto apoiado pelo CNPq).

3 Edilson Cazeloto é doutorando no programa de Pós-graduação em Comunicação e Semiótica da PUC-SP, Bolsista do CNPq e membro-fundador do CENCIB - Centro Interdisciplinar de Estudos da Comunicação e Cibercultura.
} 
Wolfgang Haug and others, when they refer to the changes that took place in the value construction process in current postmodern capitalism, focusing on communication processes and merchandize semiotization, as well as on commodification of culture. In order to comprehend current sociability, we will examine the relations between lifeworld and system, as well as the new constitution of Virno's "general intellect."

Key-Words: Globalization. Value. Society of communication.

Resumen: Valor y comunicación en el capitalismo global - Este texto busca situar la comunicación como campo de construcción del valor en la lógica del capitalismo globalizado. El rol de la comunicación en el mundo actual exige, para comprender el proceso de valorización de la mercadería, una teoría que no sea estrictamente economicista, asumiendo la necesidad de nutrirla con un conjunto de teorías oriundas de diversas áreas como la filosofía y la sociología, entre otras, incluyendo las nuevas sociabilidades de la multitud. Para efectivizar tal análisis, partiremos de la teoría marxista del valor, examinaremos las críticas de André Gorz, Paolo Virno, Wolfgang Haug $y$ otros, en las que se tematizan los cambios ocurridos en los procesos de constitución del valor en el capitalismo contemporáneo postmoderno, centralizándonos en los procesos de comunicación y semiotización de la mercadería, así como en el de mercantilización de la cultura. Para entender la nueva sociabilidad contemporánea, examinaremos las relaciones entre mundo de la vida y sistema, así como la nueva constitución del "intelecto general" de Virno.

Palavras-Clave: Globalización. Valor. Sociedad de la comunicación.

Résumé: Valeur et communication dans le capitalisme mondialisé - Ce texte cherche à situer la communication en tant que domaine où se construit la valeur dans la logique du capitalisme mondialisé. Le rôle que joue la communication dans le monde actuel exige, pour qu'il soit possible de comprendre le processus d'attribution de valeur aux marchandises, que l'on fasse appel à une théorie qui ne soit pas strictement économiciste. Cette théorie doit rendre compte du besoin de se nourrir d'un ensemble de théories posées par des domaines tels que la philosophie et la sociologie, entre autres, tenant compte des nouvelles sociabilités de la multitude. Pour réaliser cette analyse, nous partirons de la théorie marxiste de la valeur; nous examinarons les critiques d'André Gorz, Paolo Virno, Wolfgang Haug et d'autres, lorsque ces auteurs thématisent les changements intervenus dans les processus de constitution de la valeur dans le capitalisme contemporain postmoderne, centré sur des processus de communication et de sémiotisation de la marchandise, ainsi que de mercantilisation de la culture. Pour comprendre la nouvelle sociabilité contemporaine, nous étudierons les relations entre monde de la vie et système, ainsi que la nouvelle constitution de l"intellect général" chez Virno.

Mots-clés: Mondialisation.Valeur. Société de la communication. 


\section{O valor como eixo central do capitalismo}

Entendido como "modo de produção", na esteira da tradição marxista, o capitalismo é um conjunto de relações sociais que organiza a maneira pela qual o ser humano transforma a natureza e, ao fazê-lo, transforma a si mesmo. As formas sociais do trabalho, de criação e apropriação de riquezas, assumem, portanto, a centralidade do processo histórico e se tornam um critério fundamental para a compreensão das sociedades. No capitalismo essa forma historicamente determinada foi condensada por Marx no conceito de "mais-valia"; sua extração, típica das sociedades capitalistas, só é possível porque o trabalhador direto produz "mais valor" do que recebe na forma de salários. Daí a idéia de valor, não obstante as dificuldades teóricas imensas envolvidas em sua análise, revela-se como ponto nodal, critério por excelência para a compreensão de todo o edifício capitalista e chave de comparação com outros períodos históricos. Uma das questões fundamentais a se responder quando se procura compreender as sociedades contemporâneas é: no capitalismo atual houve transformações expressivas nas formas de produção e apropriação de valor?

O problema do valor sempre foi considerado um nó górdio na teoria econômica (BELLUZO, 1987 e RUBIN, 1987). Porém, é quase consenso entre os especialistas que o valor de uma mercadoria seria determinado pelo trabalho humano. O marxismo chega ao ponto de defender a perspectiva de que só tem pertinência econômica aquilo que pode ser produzido e reproduzido pelo trabalho do homem, excluindo aí os materiais brutos da natureza e as obras de arte (produtos não reprodutíveis) (RUBIN, 1987, p.183).

Já que o trabalho humano não se dá de maneira "espontânea", mas surge sempre determinado por um conjunto de relações sociais que o organizam e o possibilitam, Marx se debruça sobre a especificidade do valor nas sociedades mercantis-capitalistas. Uma de suas conclusões é que o que as caracteriza é o fato de que nelas, nenhum produtor está sujeito a forças reguladoras extra-econômicas, ou seja, a decisão de alocação de recursos (capital e trabalho) é tomada exclusivamente em função de uma previsão de retorno, baseada na percepção de movimentos do 
mercado. O produto do trabalho humano é sempre, primeiramente, uma mercadoria, criada exclusivamente para ser trocada.

Assim, o conjunto de forças produtivas de uma sociedade seria alocado de acordo com o conjunto das necessidades sociais em um dado momento, mas com vistas à expectativas de lucro. O valor, em seu aspecto qualitativo (RUBIN, 1987) é a força que regula a relação entre capacidade de produção, trabalho socialmente necessário e taxa de lucro. Se, num dado momento, o conjunto de fábricas de sapatos produz mais mercadorias do que a necessidade social, o valor individual dos sapatos cai e força uma retração da oferta pela baixa na taxa de lucro. Se produz menos, o valor aumenta e atrai investimentos para a ampliação da produção. Em ambos os casos, o resultado é uma nova distribuição das forças produtivas, tendendo a um equilíbrio temporariamente estável. Desta forma, o aspecto "qualitativo" do valor denota sua função social de organizar a distribuição do trabalho.

A análise de Marx, em que pesem todas as críticas que a sucederam, pode ser aplicável ao contexto do capitalismo industrial do séc. XIX e primeiras décadas do século XX, sendo fundamental levar em consideração algumas características do ambiente econômico no qual a teoria foi produzida, como a baixa diversidade na produção de mercadorias, a pouca influência de marcas comerciais e a baixa diversificação nas características do trabalho.

Dado que essas características empíricas sofreram grandes transformações desde a época em que Marx construiu suas teorias, cabe perguntar: qual a forma contemporânea de produção e distribuição de valor? No cenário atual, de sociedades saturadas por comunicação, hiperprodução de mercadorias, derrubada das fronteiras nacionais à circulação do capital, marketing intensivo e especialização acentuada do trabalho, quais são as estratégias vigentes para a valorização do capital?

\section{As etapas de valorização do capital}

O processo social de valorização do capital deve ser analisado em suas duas etapas constituintes: produção (incluída a distribuição) e consumo. Essas fases estão implicadas mutuamente: o momento da produção é largamente induzido por uma expectativa de lucro, que só se realizará no momento do consumo. Tal interdependência reside nas próprias características da forma-mercadoria. De um 
lado, para o capitalista, a mercadoria é promessa de lucro; de outro, para o consumidor, ela é expectativa de satisfação. É esse caráter ambivalente e irreconciliável que dinamiza a produção de valor no capitalismo (HAUG, 1996).

Assim, procederemos, num primeiro momento, a uma análise dos dois momentos em separado, articulados com as características das sociedades contemporâneas para, só em seguida, propormos um modelo que integrará produção e consumo numa visão completa do processo de valorização do capital.

\subsection{Transformações na produção: uma leitura de Gorz}

No livro "O imaterial - conhecimento, valor e capital”, o sociólogo austríaco André Gorz propõe a vigência de um estágio do capitalismo internacional calcado no conceito de "imaterial". Logo no primeiro parágrafo, a tese central é explicitada:

O capitalismo moderno, centrado sobre a valorização de grandes massas de capital fixo material, é cada vez mais rapidamente substituído por um capitalismo pós-moderno centrado na valorização de um capital dito imaterial, qualificado também de «capital humano», «capital conhecimento» ou «capital inteligência» (GORZ, 2003, p.11; GORZ, 2005, p.15)

A idéia, portanto, é que o chamado "capitalismo pós-moderno" difira de seu antecessor em uma escala mais lógica que cronológica (dada a convivência de vários modos de produção), fundamentalmente no que diz respeito ao modo de valorização do capital. Gorz retorna aos Grundrisse de Marx para localizar a previsão, em clima de profecia, de que o desenvolvimento das forças produtivas faria chegar o dia em que a medida da riqueza dependeria, cada vez menos do tempo de trabalho e cada vez mais da ciência e do desenvolvimento tecnológico. Para o autor, esta profecia já se cumpriu e a característica do capitalismo "pós-moderno" está na capacidade que ele adquiriu de colocar o "conhecimento" no centro do processo de criação de valor. Não se trata, porém, do conhecimento técnico-científico, já descrito por Marx como hipostasiado nas máquinas da indústria moderna, mas de um conjunto de saberes, não formalizados e não formalizáveis, ligados à cultura cotidiana dos trabalhadores:

(...) esse trabalho imaterial, naquilo que tem de principal, não repousa sobre os conhecimentos desses prestadores e fornecedores. Antes de mais nada, ele repousa sobre as capacidades expressivas e cooperativas que não se podem ensinar, sobre uma vivacidade presente na utilização dos saberes, e sobre uma vivacidade e que faz parte da cultura do cotidiano (GORZ, 2003, p.17; GORZ, 2005, p.19) 
A repercussão na própria noção tradicional do valor é imediata, uma vez que, ao contrário do "número de horas trabalhadas", o valor-conhecimento não é mensurável de acordo com nenhuma escala. O trabalho continua existindo e, na verdade, para alguns trabalhadores, como aqueles envolvidos em $\mathrm{P} \& \mathrm{D}$, marketing e outras formas de trabalho "imaterial", a percepção é que a esfera produtiva avança sobre o mundo privado, tornando indissociáveis os tempos de lazer e de trabalho. A idéia de valor "fora de medida" significa apenas que a unidade objetiva de comparação da tradição econômica - o número de horas trabalhadas - deixou de ser epreponderante para um grande número de mercadorias. Isso significa, para Gorz, que a necessidade de operar sobre uma lógica imaterial leva o capital a converter em valor a própria subjetividade humana ou, no repertório habermasiano, certas formas semânticas e pragmáticas do "mundo da vida" (ou mundo vivido, como preferem alguns traduzir o termo fenomenológico Lebenswelt) como a "vivacidade e a capacidade de improvisação e de cooperação", as quais, a rigor, não podem ser colocadas em comparação umas com as outras, ou seja, não podem ser medidas de acordo com uma escala comum. (GORZ, 2003, p.18; GORZ, 2005, p.19)

A impossibilidade de mensuração destas variáveis cria o "valor fora de medida”, que Gorz associa à crise do conceito de valor. Mas o problema não é apenas esse. Todas essas capacidades são, evidentemente, inalienáveis de seus possuidores. Ou seja, a empresa contemporânea, embora as tenha como um "recurso" ou "matéria-prima”, não pode simplesmente considerá-la como seu capital fixo. Em última análise, a "vivacidade, a capacidade de improvisação e cooperação", bem como outras formas pragmáticas e semânticas do mundo da vida, são atributos não comercializáveis do trabalhador e não propriedades da empresa. $\mathrm{O}$ valor criado pela exploração destas formas não está, portanto, sujeito à simples apropriação de maisvalia. O problema central do capitalismo contemporâneo, segundo Gorz, é fazer esse "capital humano funcionar como se fosse capital fixo". Impossibilitado de apropriarse diretamente a cultura cotidiana, o capital cria formas de controlar (e vender) o acesso a ela. O enfoque não é mais a extração de "mais-valia" diretamente relacionada à quantidade de trabalho extorquido, mas o monopólio sobre o acesso a conhecimentos e ao capital simbólico culturais incorporados à mercadoria. 


\subsection{Transformações no consumo: uma leitura de Haug}

Além da questão da incomensurabilidade (relativa) do valor numa sociedade talhada por formas de produção calcadas no "imaterial", essa estratégia de criação de valores implica outra conseqüência, fundamental para a afirmação da necessidade de se compreender o valor em outros termos, não estritamente econômicos. É o que Haug denomina a "Estética da mercadoria":

Cada vez mais mercadorias modificar-se-ão numa direção em cujo extremo se encontra a pura 'coisa significante'. Essa expressão tendencial, 'coisa significante', sugere que o grau de realidade e a maneira de ser do corpo da mercadoria, enquanto valor de uso, desloca-se, distanciando-se do 'objeto exterior simplesmente aparente, que satisfaz determinadas necessidades humanas por meio de suas características físicas' (a citação é de Marx), em direção à acentuação crescente do significante e do aspecto alusivo da mercadoria. Do valor de uso imediato, ligado à matéria, a importância continuará se deslocando para os pensamentos, sensações e associações vinculadas à mercadoria ou as quais supõese que outros as vincularão com a mercadoria (1996, p. 133)4.

O grau de "realidade" das mercadorias é deslocado: o valor de uso imediato não desaparece, mas é reconfigurado cada vez mais pelo significante, semiotizado (como "coisa significante") por estratégias de comunicação e de marketing, entre as quais se destaca o uso de "marcas comerciais", ou, de modo mais geral, de traços significantes que atuam como pontos nodais 5 (LACLAU, 1996). Os produtos do trabalho não são mais "anônimos": possuem uma identidade, cuidadosamente burilada pelos "tecnocratas da sensualidade" (HAUG, 1996), chamados por Reich de (1993) analistas simbólicos e por "tecnólogos do discurso", no registro de Fairclough

\footnotetext{
4 É importante ressaltar que Haug é sutil o bastante para prever o fenômeno da

"desmaterialização do valor" em uma "expressão tendencial", ou seja, na forma de uma "escala" em que o valor físico continua sempre existindo, mas perde espaço continuamente para o valor simbólico. Não se trata, portanto, de negar a objetividade da mercadoria, mas de reescalonar seu significado no tocante à construção social do valor.

5 Ponto nodal é conceito de Laclau que se refere a um significante a partir do qual se fecha uma totalização discursiva, não a partir de seu significado, mas num funcionamento dito "vazio". Veja-se o caso de dois discursos em disputa por ocasião de uma eleição para presidência. Os dois tentam dar respostas aos problemas sociais de violência e segurança da população. Um fala em aumentar a repressão e em mudar as leis, na direção de castigos mais impiedosos. Outro fala em diminuição da violência a partir de programas sociais, que integrariam no sistema econômico/sócio-cultural um contingente populacional que estaria antes atraído pelo crime organizado. Essa disputa discursiva busca tornar uma das duas totalizações discursivas a hegemônica. Ambos constroem discursos concorrentes que tentam anunciar a melhor alternativa contra a violência, a partir de pontos de costura discursiva (pontos nodais ou points de capiton, na expressão lacaniana).
} 
(2001); tal identidade é associada a uma marca, conferindo-lhe uma dimensão de exclusividade, de unicidade, de distinção dentro de uma taxonomia social-ritual de estilos de vida.

Houve uma progressiva explosão da noção de "necessidade" (HAUG: 1996, p.79 e 80). Design, embalagem, técnicas de apresentação e vendas, publicidade, marketing e outras estratégias simbólicas são máquinas de criar necessidades sempre renovadas. Tais estratégias são derivadas de condições históricas que têm o seu paradigma configurado pelo sistema da "moda", ou seja, de valorização e desvalorização simbólicas de mercadorias, para além de seu valor de uso (que, a esta altura, está tomado por uma forte idealização). Segundo Gorz (1973), até o final da $2^{\mathrm{a}}$ guerra mundial, o foco principal das inovações na indústria era o aprimoramento dos métodos de produção. A partir deste ponto, com os saltos tecnológicos pós-segunda guerra, as inovações do processo continuaram decisivas, mas se desenvolveram relativamente mais lentamente que as inovações "referentes à substância, ao estilo e à apresentação dos produtos de consumo”ø.

A estratégia adotada passou a ser o lançamento contínuo de "novos" produtos ou de pequenas modificações que "tiravam de moda" os produtos anteriores, ou seja, passou a se tratar de vender mais, para os mesmos consumidores. O "valor de uso" da mercadoria não cresce necessariamente a cada mudança, mas é a mudança em si que produz a valorização econômica (GORZ, 1973, p.221).

É neste contexto que, no capitalismo contemporâneo, o necessário e o supérfluo, o útil e o inútil, a "produção de desperdício" e a "destruição de riquezas estão "absolutamente confundidos" (GORZ, 1973, p.86). Longe deste estado de coisas representar uma crise terminal do capitalismo (como acredita o próprio Gorz), é nesta dissolução das formas tradicionais de valor que o modo de produção vem encontrando forças para se revigorar. A crise do valor sem medida é uma forma de criar e concentrar riquezas pela disseminação generalizada dos monopólios simbólicos

\footnotetext{
${ }^{6}$ Isso é apenas outra forma de dizer: produtos que receberam investimentos de capital simbólico.
} 


\section{O valor e o monopólio simbólico}

A generalização de processos semióticos e comunicacionais, tanto na produção como no consumo é modo de criar o valor sem medida ${ }^{7}$. A comparação objetiva de quantidades determinadas de trabalho ou mesmo a ancoragem em um valor de uso tornam-se secundárias em relação à percepção de atributos subjetivos como "inovação", "conhecimento", "beleza” e "praticidade”.

Esse fenômeno coloca em relevo a categoria de monopólio. $\mathrm{Na}$ teoria marxista do valor é fundamental a possibilidade de que os capitais investidos possam se transferir entre os diversos ramos de produção da sociedade. É essa possibilidade de transferência que faz o valor atuar como regulador, atraindo investimentos para as mercadorias mais valorizadas e induzindo uma taxa média de lucro na sociedade com um todo. Se isso não ocorrer, poderão se estabelecer várias taxas de lucro nos diferentes ramos de produção, o que é característica de um setor monopolizado. (RUBIN, 1987, p. 255). O monopólio se constrói quando uma mercadoria não pode mais ser substituída por outra, oferecendo ao detentor da exclusividade comercial a chance de impedir ou dificultar a transferência de capitais para competirem em seu ramo e assim estabelecer uma taxa de lucro diferente da taxa média da sociedade. $\mathrm{O}$ monopólio simbólico é a forma pela qual o capitalismo consegue criar "mercadorias únicas feitas em série”. As características derivadas da extração de valores imateriais faz com que cada empresa concorra com as demais não no plano da mercadoria e dos valores de uso, mas no plano da comunicação e da semiose, no qual não há formas objetivas de comparação entre as "imagens de produtos". A marca e o uso de valores imateriais fazem com que as mercadorias caiam no caso de exceção previsto por Marx à lei do valor: eles passam a ter um estatuto (guardadas as devidas proporções) de objeto único e não reprodutível.

As grandes empresas da atualidade valorizam seus produtos ao explorarem “rendas de monopólio”, ou seja, lucros obtidos pela exploração exclusiva de um saber,

\footnotetext{
7 De fato, o que ocorre é a perda de uma certa medida do valor, tradicionalmente derivada da noção de valor-trabalho. Embora mais fluída e imponderável, a comparação (e portanto, a mensuração) é empiricamente observável, seja pela variação do mercado de capitais, seja pelos processos milionários de fusões e aquisições que se tornaram lugar-comum no capitalismo contemporâneo.
} 
um conhecimento ou uma "imagem"8. É assim que fazem esse capital simbólico funcionar como se fosse capital fixo e, portanto, fonte de valorização, na expressão de Gorz:

O capital imaterial de empresas como a Nike, a Coca-Cola ou o McDonald's consiste principalmente no poder do monopólio, simbolizado pelo nome da marca, que elas exercem sobre o mercado e na importância da renda que esse monopólio assegura. A marca é, ela mesma, um capital, na medida em que seu prestígio e sua celebridade confere aos produtos que levam seu nome um valor simbólico monetário (GORZ, 2003, p.59 e 60)

Da mesma forma, o "conhecimento", a "criatividade", o "bom gosto" e outros atributos intangíveis do trabalho são incorporados como formas de garantir um certo grau de "exclusividade" às mercadorias, criando assim uma renda de monopólio, muitas vezes garantida pelo sistema jurídico que sanciona essas formas como "propriedade privada” das empresas.

Unificando as culturas da produção e do consumo, a valorização do capital nas sociedades contemporâneas gira em torno da transformação de cultura em mercadoria e da mercadoria em cultura. Tal "culturalização" do capitalismo já foi acenada nas obras de autores como Rifkin e Jameson, mas propomos aqui uma forma de compreendê-la em termos de uma reestruturação do processo de criação de valores, central para a análise do capitalismo contemporâneo. Para tanto, recorreremos a uma visão crítica de polarização entre Lebenswelt (mundo da vida ou mundo vivido) e Sistema, da obra de Habermas.

Na Teoria da ação comunicativa Habermas (1987) deixava isolados o mundo da vida e o sistema, como zonas de racionalidade diversas. Nos processos em que a sociedade se reproduz como sistema (administração, economia, política partidária), vige a racionalidade com respeito a fins, em que são fixados objetivos, a partir dos quais são estudadas estratégias de ação para atingi-los com base em estudos de viabilidade financeira, técnica, social etc. Nos processos de ordem simbólica, em que a sociedade se reproduz como mundo da vida, vige uma

\footnotetext{
8 É neste sentido que as leis de copyright, de proteção de marcas e de segredos industriais são vitais para o capitalismo contemporâneo. É a regulamentação jurídica que vai garantir o monopólio e não as "vantagens competitivas" do livre mercado.
} 
racionalidade dita comunicativa, em que predomina a busca de entendimento e não de objetivos fixados por balanços técnico-financeiros.

Em obra posterior, Habermas tentou melhor delinear essa báscula sistemamundo da vida, por meio de uma metáfora das eclusas (1996). Como a sociedade, que é sistema (enquanto reprodução material) e mundo da vida (enquanto reprodução cultural), faz circular mensagens e demandas da periferia das culturas para o centro sistêmico? Os processos comunicacionais e de tomada de decisão se estabelecem ao longo de um eixo centro-periferia, sendo vistos nesse modelo como estruturados por um sistema de eclusas. A área central do sistema político é formada pelas instituições governamentais, pelo sistema judicial, pelos parlamentos e partidos. Segundo Habermas, o complexo parlamentar é mais aberto para perceber e tematizar os problemas sociais, mas tem menor capacidade de lidar com problemas do que o complexo administrativo. Nas bordas da administração desenvolve-se uma periferia interna, povoada de instituições como universidades, ongs, associações profissionais, fundações etc. A clientela desse sistema se constitui em redes que estabelecem negociações contínuas com os subsistemas. Há também grupos, organizações e associações que tentam influenciar o processo político mais do ponto de vista normativo que dos interesses particulares, pertencendo a uma esfera pública dominada pelos meios de massa. O fluxo comunicativo se estabelece entre os subsistemas e os agentes socializados que pertencem às organizações da sociedade civil. Os conflitos surgidos no mundo da vida devem ser absorvidos nesse processo. (HABERMAS, 1996, p.356; PRADO in IANNI, 2000, p.109)

No momento da produção, as forças capitalistas extraem do mundo vivido os traços imateriais para construção da "mercadoria única produzida em série". São formas de conhecimentos e saberes, elementos de convivialidade, trabalho colaborativo, vivências, etc. Trata-se de processo segundo o qual o capital imaterial é posto para funcionar "como se fosse" capital fixo, largamente apoiado em formas jurídicas de propriedade, mas também nas estratégias de organização da produção do chamado "capitalismo flexível". Em outras palavras, a comunicação sistêmica bombeia as formas do mundo da vida para injetar nas mercadorias, tornando-as auráticas, fazendo-as aparecer como "únicas" a partir de um brilho semiótico que as faz não-commodities. 
Um corpo profissional especializado (analistas simbólicos na terminologia de Reich ou tecnocratas da sensualidade, em Haug) é responsável pela semiotização destas mercadorias (por meio de estratégias de marketing, publicidade e comunicação), colocando-as no mercado já com características que permitam a monopolização, ou seja, a impossibilidade de comparação com outras mercadorias em termos de valores de uso ou em termos de outras características objetivas.

Sobre essa base semiótica, as mercadorias podem ser assimiladas (compradas) não mais somente como "coisas", mas como senhas de inserção na cultura e, portanto, como elementos culturais ancorados no mundo da vida. É esse processo de "retorno" da forma-mercadoria semiotizada ao Lebenswelt que Habermas identificará como "colonização", já que, ao se tornar senha de inserção na cultura, a mercadoria carrega em si traços da lógica sistêmica. Por tratar-se de um procedimento marcado pela lógica racional em relação a fins (racionalidade instrumental) e não do telos transcendental do entendimento, a comunicação sistêmica cumpre o papel central de colocar a forma-mercadoria no coração do mundo vivido ${ }^{7}$. Assim, o processo total se mostra, ao mesmo tempo, como exploração e constituição do mundo da vida com base na produção/consumo de mercadorias.

Essa separação habermasiana de dois tipos de racionalidade perde o foco da radical transformação da esfera da produção no capitalismo globalizado. Esse movimento de mudança da valorização foi acompanhado por processos: (1) de ordem variada relativos à força de trabalho, por um lado, e (2) da esfera de produção, como um todo, por outro.

1) A força de trabalho, que significa potencial para produzir (VIRNO, 2004, p.81), que era, no final do século 19, concentrada nos atributos físicomecânicos, somente na era pós-fordista incorpora atributos que Hannah Arendt ligou à "vida da mente" (apud VIRNO, idem). A característica da força-trabalho é ser potencial, algo que se oferece ao capitalista sem materialização em produto (idem):

Aqui está o ponto crucial: lá onde algo que resiste somente como possibilidade é vendido, este algo não é separável da pessoa viva do vendedor. O corpo vivo do trabalhador é o substrato da forçatrabalho que, em si, não tem existência independente. 'A vida', bios 
puro e simples, adquire uma importância específica enquanto tabernáculo da dinâmica, do mero potencial. Os capitalistas estão interessados na vida do trabalhador, no corpo do trabalhador, por uma razão indireta: esta vida, este corpo, são o que contem a faculdade, o potencial, a dinâmica (idem:82).

Neste ponto, é possível fazer a conexão com o conceito foucaultiano de biopolítica:

O corpo vivo se torna um objeto a ser governado não por seu valor intrínseco, mas em razão do substratum do que realmente vale: força de trabalho, como agregado das mais diversas faculdades (o potencial para falar, para pensar, para lembrar, para agir etc). A vida se põe no centro da política quando o prêmio (prize) a ser ganho é a força de trabalho imaterial (idem:83).

Para Virno, porém, a biopolítica não inclui a administração da força de trabalho 9 :

ao contrário - a biopolítica é somente um efeito, uma reverberação, ou, de fato, uma articulação deste fato primário - ambos históricos e filosóficos - que consiste no comércio do potencial como potencial. A biopolítica existe sempre que aquilo que pertence à dimensão potencial da existência humana vem à frente (forefront), à experiência imediata: não a palavra falada, mas a capacidade de falar como tal; não o trabalho que realmente foi completado, mas a capacidade genérica de produzir. A dimensão potencial da existência se torna notável somente, e exclusivamente, sob a direção (guise) da força de trabalho (idem:84).

2) No capitalismo contemporâneo (dito pós-fordista) a esfera da produção se altera radicalmente. Não se trata, portanto, de um processo de deslocamento da valorização da esfera econômica da produção para a esfera de produção de sentidos (isto é, da comunicação). A própria esfera da produção é reconstruída como esfera da comunicação. A comunicação passa a constituir o processo de construção da identidade de marca, traço fundamental que dá sentido à produção, que se torna, portanto, parte do processo comunicativo sistêmico.

O recurso produtivo primário do capitalismo contemporâneo está, diz Virno, "nas habilidades lingüístico-relacionais da humanidade, no complexo de faculdades cognitivas e comunicativas que distingue o humano" (idem, p.98). Assim sendo, o

\footnotetext{
9 Aí se coloca a crítica de Virno ao conceito de biopolítica de Foucault, usado por Negri e Hardt em Império e Multidão.
} 
processo de valorização na atualidade não pode ser entendido sem considerar as tecnologias e estratégias da comunicação, a partir das quais são discursivizados (semiotizados) produtos, serviços e marcas. Os tecnólogos de discursos bombeiam formas do mundo da vida para culturalizar seus produtos e ações.

\section{O intelecto geral e a colonização}

Para finalizar, gostaríamos de conectar tais mudanças do capitalismo contemporâneo às alterações nas políticas do estado-nação, que se enfraqueceram nas últimas décadas, em paralelo com o conceito de povo como convergência em direção à unidade estatal. Na operação de contagem-por-Um-do-povo (para lembrar Badiou), de constituição do Um, fica resto. A esse resto, Paolo Virno (2004) chama “multidão", nome do múltiplo que não é povo, que está entre o individual e o coletivo, entre o privado e o público. A unidade da multidão é a linguagem, o intelecto. "O Um não é mais uma promessa, é uma premissa" (Virno,2004, p.24). É esse background da partilha (que constitui a multidão a partir de formas do mundo da vida) que o capital não cessa de colonizar para a nova produção pós-fordista. Porém, sempre fica o resto, o real lacaniano da operação de contagem por um. O termo "multidão" é proposto para dar conta da variedade de formas de vida que surge desse processo, com seus jogos de linguagem (idem, p.97).

Acompanhemos Virno. Com a queda das comunidades substanciais, não mais vige a separação entre o medo intra-comunidade e a angústia frente ao mundo externo. A multidão é a multiplicidade contemporânea que vive o "não se sentir em casa". Para enfrentar esse sentimento do "estranho" de que já falava Freud, a multidão só dispõe das formas lingüísticas do mundo da vida, do intelecto geral, como diz Virno, pois não se pode mais recorrer a códigos ético-comunicativos setoriais ou "especiais". Esse efeito-multidão constitui uma pressão do mundo da vida que não se aplaca a partir do jogo de eclusas tematizado por Habermas. $\mathrm{O}$ intelecto geral constituído pelos topoi koinoi (lugares-comuns, que se distinguem dos lugares especiais, setorizados) deve poder construir uma esfera pública, como diz Virno: "Se o ser público (publicness) do intelecto não produz o domínio de uma esfera pública, de um espaço político em que os muitos possam tender aos assuntos 
comuns, então ela produz efeitos terríveis" (idem, p.40). É o caso recente da juventude francesa que não faz parte do povo francês, mas constitui multidão.

As novas estratégias de valorização do capital estão centradas nas operações sistêmicas de comunicação, em que tudo adquire visibilidade segundo regimes precisos, a partir de certos pontos nodais que enfatizam traços significantes (os ditos valores imateriais) ao redor dos quais se constroem narrativas, com figuras e temas bem delineados. Dito de outra forma, o sistema de produção produz estratégias de comunicação ${ }^{10}$ para fazer penetrar no mundo objetivo semioses constituídas a partir de formas bombeadas do mundo da vida, de modo a exercer uma reconfiguração incessante do sistema de consumo. Veja-se que usamos aqui a expressão "estratégias de comunicação" para além de seu sentido estrito de estratégias do mix de marketing, para falar das ações das empresas na direção de construir identidades de marca, para si e para seus produtos, completamente culturalizadas pelo bombeamento das figuras e formas do mundo da vida.

${ }^{10}$ Segundo Semprini: "A comunicação - que não pode ser reduzida à mera publicidade deixa de ser mera variável do mercado de produtos para adquirir uma autonomia própria. Se no velho sistema a comunicação só tinha por função aumentar as vendas, o novo sistema adota um papel criativo. Enquanto a oferta-produto facilita ao produto um suporte físico e material, a oferta-comunicação aporta a ele os ingredientes imateriais e discursivos necessários para que possa sobreviver em um mercado minado por mil discursos contrários" (1995, p. 43). 


\section{Referências:}

BARROS, D.L. P. Teoria semiótica do texto. São Paulo, Ática, 1990.

BAUMAN, Z. Modernidade líquida. Rio de Janeiro, Jorge Zahar, 2001.

BELLUZZO, L. G. de M.. Valor e capitalismo: um ensaio sobre a economia política. São Paulo: Bienal, 1987

FAIRCLOUGH, N. Discurso e mudança social. Brasília, UnB, 2001.

GORZ, A. “A técnica, os técnicos e a luta de classe”. In: GORZ, André (org). Crítica à divisão social do trabalho. São Paulo: Martins Fontes, 1973 . L'immatériel - connaissance, valeur et capital. Paris: Galilée, 2003 . O imaterial. Conhecimento, valor e capital. São Paulo, Annablume, 2005.

HABERMAS, j. Between facts and norms. Cambridge, MIT Press, 1996. . 2 vols. Teoría de la acción comunicativa. Madri, Taurus, 1987.

HALL, S. A identidade cultural na pós-modernidade. Rio de Janeiro, DP\&A, 2001.

HARVEY, D. Condição pós-moderna.5a ed. São Paulo, Loyola, 1992.

HAUG, W. F. Crítica da estética da mercadoria. São Paulo: UNESP, 1996

JAMESON, F. Pós modernismo - A lógica cultural do capitalismo tardio. São Paulo, Ática, 1996.

KUMAR, K. Da sociedade pós-industrial à pós-moderna. Rio de Janeiro: Jorge Zahar, 1995.

LACLAU, E. Emancipación y diferencia. Buenos Aires, Ariel, 1996.

NEGRI, A e Hardt, M. Império. São Paulo: Record, 2001. . Multidão. São Paulo: Record, 2005.

PINTO, M. J. Comunicação e discurso. São Paulo: Hacker, 1999.

PRADO, J.L.A. “Teoria da comunicação e discurso sobre a globalização: crítica ou marketing?” In: Ianni, O.,Dowbor, L. et allii . Desafios da comunicação. Petrópolis, Vozes, 2000.

. "O perfil dos vencedores em Veja". In: Revista Fronteiras - Estudos Midiáticos, Porto Alegre, 2003, v. V, n. 2, p. 77-96.

PRADO, J.L.A. e Dunker, C. Žižek Crítico. SP, Hacker, 2005.

PRADO, J.L.A. e Silva, H. "Comunicação no mundo globalizado - da marketização à incomunicabilidade”. In: Questões do século 20. São Paulo, Cortez, 2003.

REICH, R. O trabalho das nações. São Paulo: Educator, 1994

RIFKIN, J. A era do acesso. São Paulo: Makron Books, 2000

RUBIN, I. I.. A teoria marxista do valor. São Paulo: Polis, 1987 
SEMPRINI, A. El marketing de la marca. Barcelona, Paidós, 1995.

VIRNO, P. A grammar of the multitude. NY, Semiotext(e), 2004.

ZILBOVICIUS, M. "Modelos de produção e produção de modelos". In: ARBIX, G. e Zilbovicius, M. De JK a FHC. A reinvenção dos carros. São Paulo, Scritta, 1997.

ŽIŽEK, S. Estudios culturales: reflexiones sobre el multiculturalismo. Buenos Aires, Paidós, 1998. 